\title{
Chapter 5 \\ Environmental Radiation Status In \\ and Around Tokyo Immediately After the TEPCO Fukushima Dai-ichi Nuclear Power Plant Disaster
}

\author{
Takeshi Iimoto, Hirofumi Fujii, Seiichi Someya, Sadao Iiizumi, \\ Takao Ebisawa, Seiichi Hirose, Etsuko Furuta, Keiji Kusama, \\ Norio Nogawa, Hiroshi Mitani, Masao Kamiko, Natsumaro Kutsuna, \\ Yasuhiro Watanabe, and Takahiko Suzuki
}

\begin{abstract}
An example of environmental radiation status in and around Tokyo immediately after the TEPCO Fukushima Dai-ichi Nuclear Power Plant (NPP) disaster is introduced. The east part of the Metropolis of Tokyo and northwest of Chiba Prefecture are located about 200-250 km south from the NPP. The local governments in the area have officially surveyed the environmental radiation status after the disaster in response to numerous requests from their citizens. The radiation surveillance by local governments has been conducted and technically guided by the radiation protection specialists. The two main goals of the surveillance are (1) to measure the ambient radiation dose (microsieverts per hour) at all the schoolyards, public parks, and representative measuring points selected by the local government, and (2) to measure the specific radioactivity (becquerels per kilogram) of drinking
\end{abstract}

\footnotetext{
T. Iimoto $(\bowtie) \bullet$ N. Nogawa $\bullet$ H. Mitani $\bullet$ M. Kamiko $\bullet$ N. Kutsuna $\bullet$ Y. Watanabe $\bullet$ T. Suzuki The University of Tokyo, 7-3-1 Hongo, Bunkyo-ku, Tokyo 113-8654, Japan

e-mail: iimoto.takeshi@mail.u-tokyo.ac.jp

H. Fujii

National Cancer Center Hospital East, Kashiwa, Japan

S. Someya

Kashiwa City Local Government, Kashiwa, Chiba, Japan

S. Iiizumi

Nagareyama City Local Government, Nagareyama, Chiba, Japan

T. Ebisawa $\bullet$ S. Hirose

Bunkyo Ward Local Government, Tokyo, Japan

E. Furuta

Ochanomizu University, Tokyo, Japan

K. Kusama

Japan Radioisotope Association, Tokyo, Japan
} 
water and local food items. In parallel with these movements, radiation experts in the University of Tokyo also organized a special correspondence team to survey the environmental radiation status immediately after the nuclear disaster. These activities and related data are introduced in this chapter.

Keywords Ambient radiation dose $\bullet$ Chiba $\bullet$ Specific radioactivity $\bullet$ Tokyo

\subsection{Introduction}

Kashiwa City and Nagareyama City are located in the northwest part of Chiba Prefecture in the metropolitan area of Tokyo, Japan. These cities are located roughly $200 \mathrm{~km}$ southward from the TEPCO Fukushima Dai-ichi Nuclear Power Plant (NPP). Bunkyo ward in Tokyo is at a distance of $220 \mathrm{~km}$ south of the NPP. The office location and other detailed information of these three cities are listed in Table 5.1.

These local governments have officially surveyed the environmental radiation status immediately after the disaster in response to requests from their citizens. The radiation surveillance in this area has been conducted and technically guided by radiation protection specialists.

The University of Tokyo is also located mainly in the metropolitan area of Tokyo, Japan. This university owns three main campuses: the Hongo campus and the Komaba campus are located in the middle-eastern part of the Metropolis of Tokyo, and the Kashiwa campus is located in the northwestern part of Chiba Prefecture. The distance between the NPP and the three campuses ranges from about 200 to $250 \mathrm{~km}$. Immediately after the nuclear disaster, the university organized a special corresponding team to survey the environmental radiation status in the site of the university. The team consists of about 20 members and includes mostly radiation protection specialists or technical experts of the university specialized in radiation measurement. This project is not research oriented; rather, the purpose is to provide, in the absence of related information, the actual data on environmental radiation immediately after the accident. This information had been continuously provided both to the university community members and to the public through a website.

Table 5.1 Location, area, and population of the cities as of April 1, 2012

\begin{tabular}{lllll}
\hline City name & Prefecture & Office location $\left(-^{\circ}-^{\prime}-^{\prime \prime}\right)$ & Area $\left(\mathrm{km}^{2}\right)$ & Population \\
\hline Kashiwa City & Chiba & $35-52-05 \mathrm{~N}$ & 114.9 & 404,252 \\
& & $139-58-35 \mathrm{E}$ & & \\
Nagareyama City & Chiba & $35-51-31 \mathrm{~N}$ & 35.28 & 166,493 \\
& & $139-54-9 \mathrm{E}$ & & \\
Bunkyo ward & Tokyo & $35-42-29 \mathrm{~N}$ & 11.31 & 201,079 \\
& & $139-45-9 \mathrm{E}$ & & \\
\hline
\end{tabular}


This chapter provides the background status and technical information on the related activities together with the estimated environmental radiation data at that time.

\subsection{Monitoring Activity and Data of Local Governments}

\subsubsection{External Exposure}

\subsubsection{Targets and Methods}

Main targets of the surveillance at the northwest of Chiba prefecture are the ambient radiation dose $\left(\mu \mathrm{Sv} \mathrm{h}^{-1}\right.$, microsieverts per hour) at all the schoolyards, public parks, and representative measuring points selected by the local governments. This activity has been based on the decision of a local forum of six cities including the two cities of Kashiwa and Nagareyama as the "Conference on Radiation Countermeasures in the Tohkatsu Area (CRCT)" [1].

The ambient dose equivalent rate around the Tohkatsu area, northwest of Chiba, was elevated after the accident, as already mentioned. The public strongly requested their local governments to monitor the ambient dose equivalent rate precisely and officially. In addition, many questions, requests for consultation, and feelings of fear assaulted the local governments. Six local governments (Kashiwa, Nagareyama, Matsudo, Noda, Abiko, and Kamagaya) in the Tohkatsu area decided to establish a new organization, CRCT, to solve the total situation officially and in cooperation. The CRCT started its official activity on June 8, 2011, after a preparation period of about 1 month. A chair of the conference is the mayor of Kashiwa City. Three specialists of radiation protection, radiation measurement, and medical science in the radiation field are also involved in the conference as supporting members for its activity. We think this is a preparation step or first step toward the real stakeholder engagement and involvement procedure in local governments for the optimization of protection. ICRP Publication 111 [2] recommends “(71) Authorities should facilitate the setting-up of local forums involving representatives of the affected population and relevant experts (e.g., health, radiation protection, agriculture authorities, etc.). These forums will allow gathering and sharing of information and favor a common assessment of the effectiveness of strategies driven by the population and the authorities."

Based on the guideline determined by the CRCT, the ambient dose rate has been monitored in the cities of Kashiwa and Nagareyama. The latest dose distribution data at the height of $5 \mathrm{~cm}$ (for identifying contaminated areas), $50 \mathrm{~cm}$ (for dosimetry of children), and $100 \mathrm{~cm}$ (for adults) from the ground in the cities can be seen against the background of a Google map on the government web pages. Monitoring targets are all schoolyards (nursery schools, kindergartens, child centers, elementary schools, and high schools), parks and sports grounds, the exterior 
of local government institutions, bus terminals, city streets, city pools, and around sewage adjustment ponds and waste disposal sites. These sites are monitored by energy-response compensation gamma survey meters with $\mathrm{NaI}(\mathrm{Tl})$ or $\mathrm{CsI}(\mathrm{Tl})$ scintillation detectors. These survey meters are also selected based on the CRCT guideline. The monitoring frequency for each investigation point was more than once monthly. These monitoring activities have also been conducted by Bunkyo ward in Tokyo.

The local governments distributed one (or two) electric personal dose meter(s) to all the public/private schools in Kashiwa City and Nagareyama City. The purpose was to announce the monthly dose of children for their routine activities to the citizens, and to determine an actual annual dose based on the measured results; this is representative of a child's personal dose, not the ambient dose. Unfortunately, at the early stages the citizens tended to worry about the effects of an extremely small area's high contamination, a so-called micro hot spot. The cities would like to do a quantitative analysis to show the actual level of the exposure dose around the micro hot spot rather than a qualitative explanation. Electric personal dose meters in each school were given to a representative staff member, and the meters were worn at the chest height of a typical child. The personal dose meter was operated all day long $(24 \mathrm{~h})$. At nights and on holidays the dose meters were placed in rooms of the schools.

\subsubsection{Data and Information}

The following data are major results of activities conducted by the three local governments as described in the earlier section.

The ambient radiation dose in the cities has been surveyed since around May 2011. The highest value of the ambient radiation dose was $0.65 \mu \mathrm{Sv} \mathrm{h}^{-1}$ in Kashiwa City, $0.58 \mu \mathrm{Sv} \mathrm{h}^{-1}$ in Nagareyama City and $0.22 \mu \mathrm{Sv} \mathrm{h}^{-1}$ in Bunkyo ward at the height of $1 \mathrm{~m}$ from the ground among all the monitoring points. These values include the natural background dose rate $\left(0.04-0.08 \mu \mathrm{Sv} \mathrm{h} \mathrm{h}^{-1}\right)$.

Figure 5.1 shows an example of annual average dose at schools in Kashiwa City measured by personal dose meters from September 1, 2011 to August 31, 2012. The data recorded in this project have been announced on the official website in the city every month. This activity and information greatly reduced the number of questions or requests for consultations from citizens living around the "micro hot spot" area.

\subsubsection{Internal Exposure}

\subsubsection{Targets and Methods}

Local governments were strongly encouraged to monitor the specific radioactivity (Bq kg-1, becquerels per kilogram) of local food and drinking water under the present popular policy of "Local Production for Local Consumption" in Japan. 


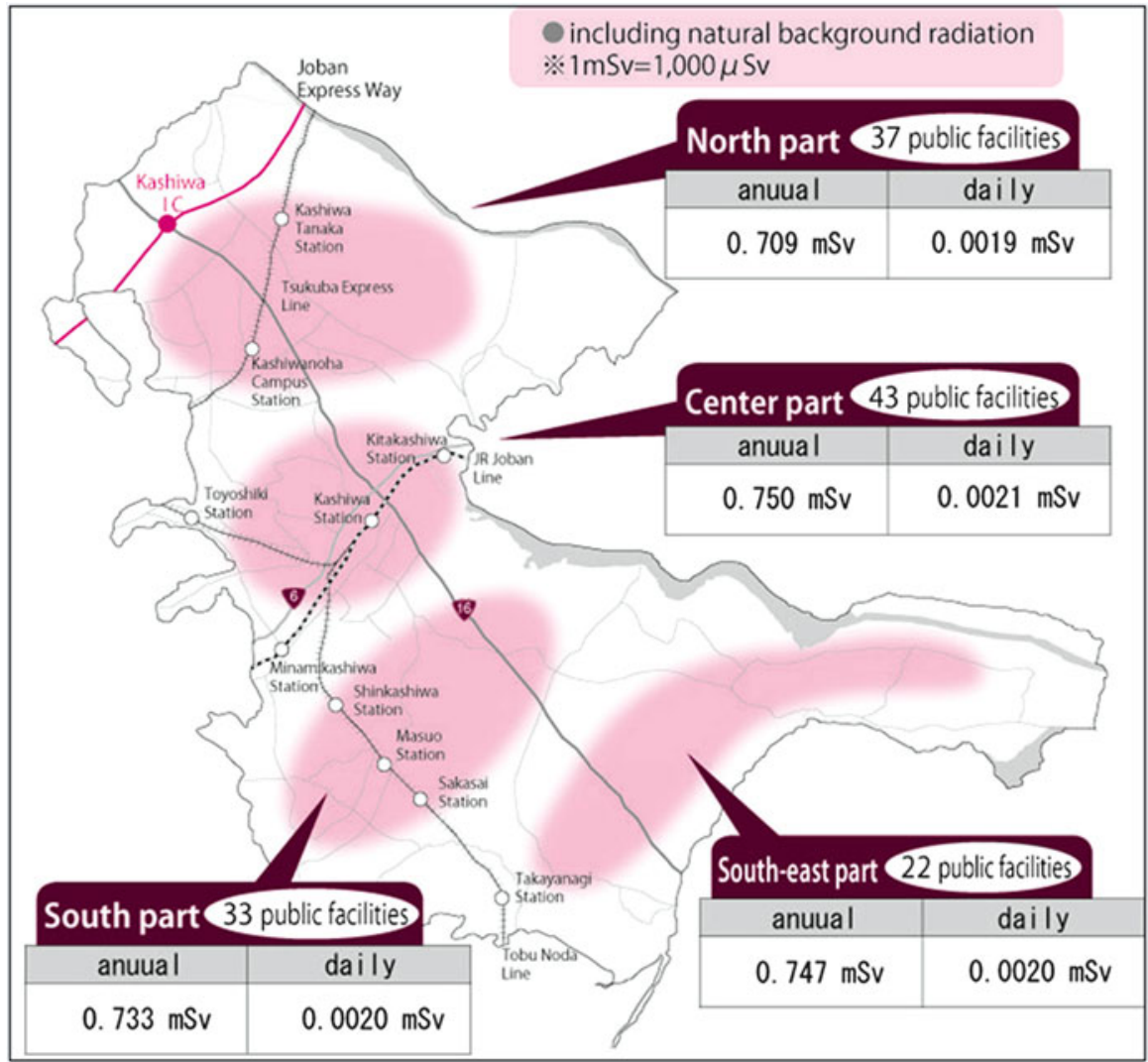

Fig. 5.1 Annual average dose at schools in Kashiwa City measured by personal dose meters from September 1, 2011 to August 31, 2012. Kashiwa City is located in the northwest part of Chiba Prefecture in the metropolitan area of Tokyo, Japan, roughly $200 \mathrm{~km}$ to the south of the TEPCO Fukushima Dai-ichi Nuclear Power Plant

In parallel with the national survey and the relating prefectures' survey, the three cities have been continuing to monitor various materials and to announce the results to their citizens. The target materials are school lunch and food items, local food items, tap water, and supplied water, water in school or public pools, waste disposal, etc. For example, the actual lunch supplied for 1 week in each school was monitored by a $\mathrm{Ge}$ semiconductor or $\mathrm{NaI}(\mathrm{Tl})$ scintillation spectroscopy system.

The sampling procedures of local food items are as follows: for example, in Kashiwa City, (1) the types of food to be monitored from the representative four areas of the city are discussed and selected among agricultural cooperatives, farmers, and city officers; (2) city officers ask the selected farmers for basic information on these food items, for example, the planting season; and (3) local food items are sampled, weighed, and passed on to monitoring rooms. The food samples are then measured by a $\mathrm{NaI}(\mathrm{Tl})$ scintillation spectroscopy system (a 15-min measurement with a 500-ml Marinelli beaker, where the minimum detectable limit concentration 
Table 5.2 Specific radioactivity of service water in Nagareyama purification plant in April, 2011

\begin{tabular}{llllllllll}
\hline Date in April 2011 & 22 & 23 & 24 & 25 & 26 & 27 & 28 & 29 & 30 \\
\hline $\mathrm{Bq} \mathrm{kg}^{-1}$ of ${ }^{131} \mathrm{I}$ & - & 110 & - & 33 & 14 & - & $\mathrm{ND}$ & $\mathrm{ND}$ & $\mathrm{ND}$ \\
\hline,- no data \\
ND, less than lower detectable limit concentration
\end{tabular}

is estimated as $6 \mathrm{~Bq} \mathrm{~kg}^{-1}$ ). As of the end of August 2012, about 800 local food samples have been monitored using this procedure in Kashiwa City. These data have been reported on the city website as well as in a bimonthly report in the public relations magazine of the local government.

Nagareyama City and Bunkyo ward have also monitored their food materials and opened all data to the public similarly.

\subsubsection{Data and Information}

The following data are major results of activities conducted by the three local governments as described in the earlier section.

The specific radioactivity of the drinking water and of the local food items has been surveyed since March 2011 and since April 2011, respectively, for example in Nagareyama City. As of March 23, 2011, only one sample of service water showed $110 \mathrm{~Bq} \mathrm{~kg}^{-1}$ of ${ }^{131} \mathrm{I}$; no water sample other than this has been found to exceed the limits until now, 2013, as shown in Table 5.2.

The highest specific radioactivity was $831 \mathrm{~Bq} \mathrm{~kg}^{-1}$ of ${ }^{134+137} \mathrm{Cs}$, measured for a flat Japanese mushroom that was cultivated on Japanese oak logs, which were sampled in Nagareyama City on November 16, 2011. This was detected during the monitoring carried out for Chiba Prefecture. In addition, the radioactivity levels of an outdoor bamboo shoot and a flat mushroom also temporarily exceeded the acceptable limits for the specific concentration of food items. These were also detected by Chiba Prefecture. According to the monitoring results for Nagareyama City, disaster-induced specific radioactivity of all surveyed food items (excluding the items listed above) was found to be below the limits for intake dose (see Tables 5.3 and 5.4).

In Kashiwa City, about 800 samples of the local food items, which were grown and circulated in the city as of the end of August 2012, have been checked using a $\mathrm{NaI}(\mathrm{Tl})$ scintillation spectroscopy system. An outdoor bamboo shoot sampled in the city on April 9, 2012 showed $170 \mathrm{~Bq} \mathrm{~kg}^{-1}$ as the specific radioactivity of ${ }^{134+137} \mathrm{Cs}$. In addition, a crucian carp sampled in Teganuma Lake on June 23, 2012 showed $241 \mathrm{~Bq} \mathrm{~kg}^{-1}$. Specific radioactivity of all surveyed samples, other than these three, has been below the limits.

In Bunkyo ward, no water sample supplied to the city has exceeded the national limits for intake dose, based on the monitoring at their local purification plants. The specific radioactivity of school lunches was also surveyed four times (in December 
Table 5.3 Specific radioactivity $\left({ }^{134+137} \mathrm{Cs}\right)$ of local food items in Nagareyama City, measured after April 13, 2012

\begin{tabular}{lllll}
\hline $\mathrm{Bq} \mathrm{kg}^{-1}$ & $<25$ & $>25,<50$ & $>50,<100$ & $>100<$ \\
\hline Number of items & 269 & 4 & 0 & 0
\end{tabular}

This monitoring was carried out by the Nagareyama City local government

Table 5.4 Specific radioactivity $\left({ }^{134+137} \mathrm{Cs}\right)$ of local food items in Nagareyama City, measured before April 13, 2012

\begin{tabular}{llll}
\hline $\mathrm{Bq} \mathrm{kg}^{-1}$ & $<20$ & $>20,<500$ & $>500$ \\
\hline No. of items & 203 & 2 & 0 \\
\hline $\begin{array}{l}\text { This monitoring is carried out by the Nagareyama City local } \\
\text { government }\end{array}$
\end{tabular}

2011, and May, July, and September 2012) by the local government. Thus far, 162 sets of school lunches in the city have been checked using a Ge spectroscopy system. The highest specific radioactivity of ${ }^{134+137} \mathrm{Cs}$ was detected as $2.5 \mathrm{~Bq} \mathrm{~kg}^{-1}$ in a school lunch and 15.4 Bq kg-1 in milk, which were recorded in December 2011.

\subsection{Monitoring Activity and Data of the University of Tokyo}

\subsubsection{Targets and Methods}

The two primary targets of the surveillance were (1) the ambient radiation dose $\left(\mu \mathrm{Sv} \mathrm{h}^{-1}\right)$ and (2) the specific radioactivity $\left(\mathrm{Bq} \mathrm{kg}^{-1}\right)$ of rainwater and of soil around the surface of the ground, which was used to show the level of contamination.

To measure the ambient dose, well-calibrated $\mathrm{NaI}(\mathrm{Tl})$ scintillation survey meters of the energy compensation type were used. The elevations at which measurements were performed were adequately selected as $1 \mathrm{~m}$ (for the standard height of adults in the Kashiwa campus and the Hongo campus), or $15 \mathrm{~m}$ for the airborne radioactivity survey in the Komaba campus.

To measure the specific radioactivity of soil, $\mathrm{NaI}(\mathrm{Tl})$ scintillation and/or Ge semiconductor spectroscopy systems were used. Soil materials were sampled from the surface of the ground, from a layer between 0 and $1 \mathrm{~cm}$ depth (for surface layer target method) or from a layer between 0 and $5 \mathrm{~cm}$ depth (for standard target method). The sampled soil was weighed and measured as is (without being dried). Specific radioactivity of samples of rainwater was also measured. The ambient dose data had been reported every day on the website. In addition, the data had been published in the portal site magazine of the university. Soil contamination data were reported occasionally and periodically. 


\subsubsection{Data and Information}

Since the morning of March 15, 2011, continuous survey of the ambient radiation dose rate has been officially performed at the selected representative locations on the campus sites. The first peak dose of $0.72 \mu \mathrm{Sv} \mathrm{h}^{-1}$ was observed around 2:30 pm on March 15, 2011, in the Kashiwa campus, and the second peak dose of $0.80 \mu \mathrm{Sv} \mathrm{h}{ }^{-1}$ was observed around 11:00 am on March 21, 2011, when the first rain fell after the NPP accident. The elevation at which these measurements were performed was $1 \mathrm{~m}$ above the ground.

The large reduction of ambient radiation dose rate was observed after 20 days following March 21, 2011, and afterward the ambient radiation dose gradually reduced until the continuous surveillance ended at the end of March 2012. At that time, the representative ambient dose rates of the campuses were measured to be about $0.23 \mu \mathrm{Sv} \mathrm{h}{ }^{-1}$ for the Kashiwa campus and about $0.11 \mu \mathrm{Sv} \mathrm{h}^{-1}$ for the Hongo campus (at $1 \mathrm{~m}$ above the ground). These measured values included the natural background dose rate.

Area distribution of ambient radiation dose was measured at 1,516 points with a distance of $6 \mathrm{~m}$ between them in the site of the Kashiwa campus from October 10 to November 10, 2011. At the elevation of $1 \mathrm{~m}$ above the ground, the average dose rate was $0.3 \mu \mathrm{Sv} \mathrm{h}{ }^{-1}$, and more than $80 \%$ of measurements yielded values less than $0.35 \mu \mathrm{Sv} \mathrm{h}{ }^{-1}$. Some measurement spots where the radiation dose indicated more than $0.6 \mu \mathrm{Sv} \mathrm{h}^{-1}$ at the elevation of $1 \mathrm{~m}$ and more than $1.0 \mu \mathrm{Sv} \mathrm{h} \mathrm{h}^{-1}$ at the elevation of $5 \mathrm{~cm}$ have been decontaminated, following the corresponding plan determined by the Kashiwa local government. These spots were found in drainage pathways, such as rain gutters and underneath downspouts. After the contaminated surface soil was removed, the observed radiation dose at the elevation of $5 \mathrm{~cm}$ above the ground dropped by about 70-80\% from the level of the predecontamination values.

From March 13, radiation experts in the Komaba campus had started measuring the ambient radiation dose rate. An automatic ambient radiation monitoring system was installed about $15 \mathrm{~m}$ above the ground. During the measurement period, the maximal level of the ambient radiation dose rate in the Komaba campus was about $0.52 \mu \mathrm{Sv} \mathrm{h}{ }^{-1}$, observed at 7:00 pm on March 15, 2011. By the end of April 2011, the radiation dose rate at the elevation of $15 \mathrm{~m}$ was reduced almost to the same level as the natural background radiation $\left(0.05-0.06 \mu \mathrm{Sv} \mathrm{h}{ }^{-1}\right)$.

As of mid-April 2011, 0.2-0.35 kBq kg-1 of ${ }^{131} \mathrm{I}$ and $1.0-1.5 \mathrm{kBq} \mathrm{kg}^{-1}$ of ${ }^{134+137} \mathrm{Cs}$ were measured in soil samples in the Kashiwa campus using the standard target method. On March 29, 2011, $7.8 \mathrm{kBq} \mathrm{kg}^{-1}$ of ${ }^{131} \mathrm{I}$ and $2.7 \mathrm{kBq} \mathrm{kg}^{-1}$ of ${ }^{134+137} \mathrm{Cs}$ were measured in soil samples in the Hongo campus using the surface layer target method. On March 22, 2011, $3.2 \mathrm{kBq}^{-1}$ of ${ }^{131} \mathrm{I}$ and $0.18 \mathrm{kBq} \mathrm{l}^{-1}$ of ${ }^{134+137} \mathrm{Cs}$ were measured in a rainwater sample on the Hongo campus site.

Box 5.1 indicates a member list of the special corresponding team appointed to survey the environmental radiation status in the University of Tokyo. We wish to express our sincere gratitude to the members for their enormous contribution in the related activity. 


\section{Box 5.1 Members of the special corresponding team appointed to survey the environmental radiation status in the University of Tokyo \\ T. Iimoto, N. Nogawa, K. Tao, S. Higaki, Y. Koike, N. Kosaka, T, Suzuki, A. Kobashi, M. Tanikawa, K. Tanoi, M. Hirota, Y, Yie, K. Nozawa, H. Mitani, N. Kutsuna, T. Watanabe, K. Kamiko, Y. Watanabe, Y. Kamimura, and Staffs of Division for Environment, Health and Safety and Staffs of Environment, Health and Safety Department.}

\subsection{Conclusion}

An example outline of the environmental radiation status in and around Tokyo immediately after the nuclear disaster of the TEPCO Fukushima Dai-ichi NPP has been presented. The background status and technical information of the related measuring activities and the estimated data were introduced, focusing on activities of three local governments and the University of Tokyo.

Kashiwa City and Nagareyama City are now continuing monitoring of environmental radiation and operating their decontamination program following the local government policies. Their newest data can be checked and traced through their official website.

Open Access This article is distributed under the terms of the Creative Commons Attribution Noncommercial License which permits any noncommercial use, distribution, and reproduction in any medium, provided the original author(s) and source are credited.

\section{References}

1. Iimoto T, Fujii H, Oda S, Nakamura T, Hayashi R, Kuroda R, Furusawa M, Umekage T, Ohkubo Y (2012) Measures against increased environmental radiation dose by the Tepco Fukushima Dai-ichi NPP accident in some local governments in the Tokyo metropolitan area: focusing on examples of both Kashiwa and Nagareyama cities in Chiba prefecture. Radiat Prot Dosim 152(1-3):210-214. doi:10.1093/rpd/ncs224

2. Annals of the ICRP, ICRP Publication 111. Application of the commission's recommendations to the protection of people living long-term contaminated areas after a nuclear accident or a radiation emergency (2009) ISSN 0146-6453, ISBN 978-0-7020-4191-4, 39(3) 